\title{
CINESIOTERAPIA NAS POLINEUROPATIAS PERIFERICAS EM CRIANÇAS
}

\author{
Abrão AnghLnah * \\ Alberto Alencar Carvalho**
}

O presente trabalho visa a cívulgar os resultados do emprêgo de exercícios terapêuticos em crianças com déficits motores decorrentes de polineuropatias periféricas, observadas durante o periodo de 1952 a 1962.

\section{MATERIAL E METODOS}

O material consta de 24 crianças com idades variando de 1 a 12 anos: 16 casos eram devidos a polirradiculoneurite $12 \mathrm{com}$ tetraplegia, 2 com tetraparesla e 2 com paraplegia crural flácida) e 7 a processos tóxicos pós-difteria ( 6 com tetraparesia e um com tetraplegia); em um caso (com tetraparesia) a etiologia nāo pôde ser apurada. Todos os pacientes foram medicados com ACTH e cortisona durante a fase aguda.

O programa cinesioterápico levou em conta os periodos evolutivos das polineuropatias. Na fase aguda procurou-se manter os vários segmentos afetados em atitude anatômica, sendo feita apenas movimentação passiva (15 vēzes para cada articulação de 3 em 3 horas); na fase subaguda (com ou sem sinais de degeneraçáo), antes de traçar o programa de exercicios, foi feita a avaliação da fôrça muscular mediante os testes musculares manuais adotados pela National Foundation for Infantile Paralysis (New York) com algumas modificaçoes ${ }^{1,2}$.

Por êste método a förça é representada numèricamente ou em percentagens, desde que se leve em conta determinados fatòres (amplitude do movimento, açāo da gravidade e resistencia oposta pelo examinador): considera-se como normal (igual a $100 \%$ ) o deslocamento do segmento em tôda sua amplitude, contra a ação da gravidade e resisténcia máxima oposta pelo examinador; o valor será de $75 \%$ quando o segmento se desloca em tôda sua amplitude, contra a ação da gravidade e resistência parcial; de 50\% quando o segmento se desloca contra a açāo da gravidade e em tôda sua amplitude; de $25 \%$ quando o segmento só se desloca após a retirada da ação da gravidade; de $10 \%$ quando houver esboço de contração sem movimento articular; de 0 (zero) quando nāo houver esboço de contração. Em crianças menores de dois anos (qua colaboram pouco) e sem distúrbios acentuados da sensibilidade a avallação foi feita obedecendo a critério semelhante, sendo, entretanto, os segmentos testados submetidos a estímulos com objeto de ponta romba (nociceptivos) para que se movimentassem.

Feita a avaliaçăo do déficit muscular, o programa cinesioterápico foi traçado no sentido de fortalecer os grupos musculares afetados e desenvolver a amplitude

Trabalho da Clínica Neurológica da Fac. Med. da Univ. de São Paulo (Prof. Adherbal Tolosa), apresentado na I Reuniāo da Academia Brasileira de Neurologia realizada em Curitiba (Paraná), 30 de junho a 6 de julho de 1963: * Médíco adjunto; ** Médico estagiário. 
do movimento. Assim, por exemplo, se num grupo muscular (flexores do antebraço sôbre o braço) a fôrça fór igual a 0 ou $10 \%$, não devem ser incluídos no programa cinésico exercicios ativos contrários à ação da gravidade, pois que para tanto seria necessário grau de fôrça igual ou maior que 50\%. O antebraço com fôrça inicial de 0 a $10 \%$ é colocado em extensâo e semipronação sôbre superfície plana, posição na qual é excluída a açăo da gravidade; o paciente, auxiliado pelo técnico, se esforça por fletir o antebraço, deslizando-o pouco a pouco em direçâo ao tórax; com a seqüência de exercicios o paciente consegue atingir, por seu próprio esfórço, mas sempre apoiado sôbre um plano horizontal, o máximo de amplitude, ou seja, movimentar seu antebraço com fôrça de $25 \%$. Uiteriormente são utilizados, simultâneamente, duas ordens de exercicios: a) a partir da posicāo anterior, opōe-se resistèncla progressiva à flexão do antebraço; b) com o antebraço em extensāo e supinação solicita-se ao paciente a flexāo do antebraço em direção contrária à da ação da gravidade. A partir do momento em que o paciente consegue executar o movimento contra a açāo da gravidade ( $50 \%$ de fórça), são adicionados exercícios com resistência progressiva (De Lorme $^{3}$ ) até que o paciente consiga execular a flexāo contra resisténcia máxima, ou seja, movimentar o antebraço com fôrça correspondente a $100 \%$.

o exame da capacidade motora mediante testes musculares manuais constitui meio para orientar o programa de recuperação de fôrça e aumentar a amplitude de movimentos. Entretanto, os movimentos readquiridos mediante a cinesioterapia são elementares e nem sempre são suficientes para o exercicio pleno de atividades funcionais complexas. Assim, apesar da possivel persistência de sinais neurológicos (arreflexia profunda e hjpotrofia muscular), bem como de déficit parcial de força em um ou outro grupo muscular, deverão ser feitos exereicios visando a recuperação de alguns movimentos complexos para a execução de atividades básicas da vida diária.

Assim, nos 24 pacientes referidos neste trabalho - nenhum dos quais conseguia locomover-se e todos apresentavam acentuado déficit de preensão - a par de exercícios que visavam desenvolver a ampiitude e a fôrça de movimentos elementares, foram programados exercícios para a recuperaçāo de alguns movimentos complexos de maior importância para as atividades da vida diária: mudar de decúbito, sentar-se e deitar no leito, passar do leito para cadeira de rodas e vice-versa, levantar e sentar em cadeira, equilibrar-se, andar entre barras paralelas, andar com apoio (bengalas ou muletas) e depois sem apoio, subir e descer escadas, segurar objetos habitualmente utilizados para a higiene e para a alimentação.

\section{RESULTADOS}

Para avaliar os resultados que foram reunidos no quadro 1, considerou-se a capacidade funcional do paciente por ocasião da alta.

No que respeita à topografia e grau, o déficit motor apresentado pelas 24 crianças referidas neste trabalho era assim distribuido: tetraplegia em 13 casos, tetraparesia em 9 e paraplegia crural flácída em 2.

Submetidos à terapêutica medicamentosa adequada (ACTH e cortisona) e à cínesioterapia, 23 dos pacientes $(99,8 \%)$ obtiveram recuperação da preensão e conseguiram andar por seus próprios meios; em um caso (caso 4), a recuperação da marcha foi parcial, sendo possivel apenas a deambulaçāo com apoio.

O tempo médio de tratamento cinesioterápico durante a internação foi de 45 dias.

O tempo de duração da incapacidade antes do inicio da cinesioterapia (média de 30 dias) e as idades dos pacientes não influiram sensivelmente na duraçâo média do tratamento até a recuperação de capacidade funcional básica que permitiu a alta hospitalar. 


\begin{tabular}{|c|c|c|c|c|c|c|c|c|}
\hline \multirow{2}{*}{ Caso } & \multirow{2}{*}{ Nome } & \multirow{2}{*}{ Registro } & \multirow{2}{*}{$\begin{array}{l}\text { Idade } \\
\text { (anos) }\end{array}$} & \multirow{2}{*}{$\begin{array}{c}\text { Tipo de } \\
\text { incapacidade }\end{array}$} & \multirow{2}{*}{ 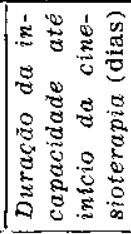 } & \multirow{2}{*}{ 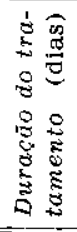 } & \multicolumn{2}{|c|}{$\begin{array}{l}\text { Grau de recupe } \\
\text { racão funcional }\end{array}$} \\
\hline & & & & & & & MM.SS. & $M M . I I$ \\
\hline 1 & MIC & 1887 & 5 & Tetraparesia & 49 & 11 & $\mathrm{RP}$ & RM \\
\hline 2 & VLA & 2402 & 7 & Tetraplegia & 23 & 12 & $\mathrm{RP}$ & $\mathrm{RM}$ \\
\hline 3 & MG & 2656 & 7 & Tetraplegia & 50 & 68 & $\mathrm{RP}$ & $\mathrm{RM}$ \\
\hline 4 & ZAS & 2812 & 4 & $\begin{array}{c}\text { Paraplegia } \\
\text { crural }\end{array}$ & 25 & 27 & - & MA \\
\hline 5 & IC & 3044 & 4 & Tetraparesia & 22 & 40 & $\mathrm{RP}$ & $R M$ \\
\hline 6 & MCT & 3492 & 1 & Tetraplegia & 25 & 64 & $R P$ & RM \\
\hline 7 & FBI & 3572 & 12 & Tetraplegia & 21. & 34 & $R P$ & $\mathrm{RM}$ \\
\hline 8 & MSS & 3807 & 7 & Tetraplegia & 19 & 43 & $\mathrm{RP}$ & $\mathrm{RM}$ \\
\hline 9 & VLA & 4505 & 10 & Tetraplegia & 16 & 52 & $\mathrm{RP}$ & $\mathrm{RM}$ \\
\hline 10 & EAS & 4616 & 8 & Tetraplegia & 15 & 40 & $\mathrm{RP}$ & $\mathrm{RM}$ \\
\hline 11 & APM & 5368 & 8 & Tetraplegia & 25 & 34 & RP & RM \\
\hline 12 & NMR & 5413 & 8 & Tetraplegia & 15 & 26 & $\mathrm{RP}$ & $\mathrm{RM}$ \\
\hline 13 & $\mathrm{BA}$ & C.P. & 9 & Tetraplegia & 10 & 19 & $\mathbf{R P}$ & $\mathrm{RM}$ \\
\hline 14 & $\mathrm{FCB}$ & C.P. & 8 & $\begin{array}{c}\text { Paraplegia } \\
\text { crural }\end{array}$ & 14 & 136 & - & RM \\
\hline 15 & MNB & C.P. & 4 & Tetraplegia & 16 & & $\mathrm{RP}$ & $\mathbf{R M}$ \\
\hline 16 & MDP & C.P. & 5 & Tetraplegla & 15 & 9 & $\mathrm{RP}$ & RM \\
\hline 17 & $\mathrm{AM}$ & 2749 & 3 & Tetraparesia & 101 & 45 & $\mathrm{RP}$ & RM \\
\hline 18 & SAF & 3914 & 1 & Tetraplegia & 2 & 76 & RP & $\mathrm{RM}$ \\
\hline 19 & JBR & 4682 & 4 & Tetraparesia & 42 & 54 & $\mathrm{RP}$ & $\mathrm{RM}$ \\
\hline 20 & $\mathrm{JCD}$ & 4746 & 2 & Tetraparesia & 64 & 34 & $R P$ & $\mathrm{RM}$ \\
\hline 21 & NBF & 4760 & 5 & Tetraparesia & 13 & 30 & $\mathrm{RP}$ & $\mathrm{RM}$ \\
\hline 22 & LGB & C.P. & 1 & Tetraparesia & 7 & 30 & $R P$ & $\mathrm{RM}$ \\
\hline 23 & MTG & C.P. & 5 & Tetraparesia & 45 & 21 & RP & RM \\
\hline 24 & $\mathrm{PZ}$ & 3207 & 11 & Tetraparesia & 90 & 24 & $\mathrm{RP}$ & $\mathrm{RM}$ \\
\hline
\end{tabular}

Quadro 1 - Resultados da cinesioterapia em crianças com polineuropatias. Nos casos 1 a 16 o processo neurológico foi secundário a moléstia infecciosa; nos casos 17 a 23 tratava-se de polineuropatia pós-diftérica; no caso 24 a etiologia nảo foi esclarecida. Legenda: MM.SS., membros superiores; MM.Ir., membros inferiores; RP, recuperação da preensio; $\mathrm{RM}$, recuperaça da marcha; MA, marcha com apoio.

\section{COMFNTARIOS}

A avaliação terapêutica em polineuropatias é difícil por ser a sintomatologia polimorfa e a evolução diversa, disso decorrendo grandes variaçōes quanto aos déficits motores e à perda de funções de vital importância.

Mediante testes musculares manuais deve-se verificar, o mais precocemente possivel, quais são os grupos musculares 'mais atingidos e, com base nesse exame, estabelecer programa de exercícios a serem utilizados imediatamente, procurando manter o equilíbrio neuromuscular, até que se dê o retôrno do influxo nervoso. 
Os resultados obtidos permitem admitir que as polineuropatias periféricas em crianças, quando convenientemente medicadas e submetidas à cinesioterapia evoluem de forma bastante favorável, sendo o prognóstico bom na maioria dos casos quando se considera apenas a movimentação elementar e a recuperação de duas funções básicas complexas, como sejam a preensão e a marcha.

Nas polineuropatias de qualquer natureza a cinesioterapia é coadjuvante precioso da terapêutica etiológica ou sintomática no sentido de acelerar o processo de recuperação da fôrça muscular e para evitar que se instalem seqüelas irremissíveis.

\section{RESUMO}

Os autores relatam os efeitos da cinesioterapia em 24 crianças portadoras de défjicits motores por lesão de nervos periféricos. A avaliação do grau de fôrça muscular foi feita mediante o emprêgo de testes musculares manuais, adotados pela National Foundation for Infantile Paralysis (New York) e, de acôrdo com os déficits musculares existentes, foi seguido programa cinesioterápico com base nos exercícios de resistência progressiva de De Lorme; além disso os pacientes foram submetidos a exercicios para recuperar e desenvolver funções hásicas da vida diária (preensão e marcha). Todos os pacientes foram medicados com ACTH e cortisona durante a fase aguda.

Em 23 pacientes $(99,8 \%)$ foi possível obter a recuperação da capacidade de preensão e da marcha: em um $(0,2 \%)$ a recuperação da marcha foi parcial. O tempo médio de cinesioterapia durante a internação foi de 45 dias.

Estes resultados mostram que as polineuropatias periféricas em fase aguda são beneficiadas com a hormonioterapia e que a recuperação motora é abreviada com a utilização precoce da cinesioterapia.

A cinesioterapia não só evita que se instalem seqüelas irremissiveis, como conserva o mecanismo efetor durante a regeneração nervosa, constituindo-se em valioso auxiliar da terapêutica medicamentosa.

\section{SUMMARY}

\section{Kynesiotherapy in children with peripheric polyneuropathies.}

The authors describe the effects of kynesiotherapy in 24 children with motor impairments caused by peripheric nerve lesions. The evaluation of muscular strength was performed by manual musculary tests, used by the N.F.I.P. (N.Y.) and, according to the musculary deficits in each case, a kynesiotherapy program was followed, based on the progressive resistance exercises of De Lorme. The patients were also submitted to exercises to develop basic functions of daily living (prehension and walking). 
All the patients were treated with ACTH and cortisone during the acute period. In 23 patients $(99.8 \%)$ it was possible to obtain the recuperation of the ability to prehension and walking; in one case $(0.2 \%)$, a partial recuperation of walk. The rate duration of kynesiotherapy during the period of internation was 45 days.

These results show that peripheric polineuropathies are beneficiated by hormonetherapy in the acute period and the motor recuperation is shortened using early kynesiotherapy.

\section{REFERENCIAS}

1. ANGHiNaH, A. - Avaliação clinica quantitativa de incapacidades motoras. Arq. Neuro-Psiquiat. (São Paulo), 15:148-154, 1957. 2. DANIELS, L.; WILlIAMS, M.; WorthinghaM, C. - Muscle Testing. Ed. W. B. Saunders Co., Philadelphia, 1952. 3. De LORME, T. C. - Restoration of muscular power by heavy-resistence exercices. J, Bone Joint Surg., 27:645-667, 1945.

Clínica Neurológica - Caixa Postal 3461 - São Paulo, SP - Brasil. 